\title{
OCCUPATIONAL DISEASES. EPIDEMIOLOGICAL TRENDS OF THE OCCUPATIONAL DUST DISEASES, PREVENTION AND EARLY DIAGNOSIS
}

\author{
Petrova E. \\ Center on Occupational diseases, MU, Clinic on Occupational Diseases, \\ University hospital Saint Ivan Rilski, Sofia \\ Reviewed by: Assoc. Prof. St. Popova
}

\begin{abstract}
The aim of the study was to present the main groups of occupational diseases In Bulgaria, as well as the epidemiological trends and the prognosis of the benign and malignant occupational dust diseases in workers exposed to non-organic dust up to $1985 y$, and during 1985 - 2003 periods, as well as to propose ideas for adequate medical check up.Material and methods. We investigated the all number of patients with benign and malignant occupational dust diseases in Bulgaria during the period 1985 - 2000y was investigated. The information was obtained by the last regional departments for medical service of pneumoconioses in Bulgaria. Additionally, we investigated dust diseases in 116 miners from brown coal mining in Bobov dol mine, 113p. - from black coal mining in Balkan mine, 53p. - from anthracite coal mining in Antra, 198 - from lead-zinc ore mining in Lucky, Gorubso, and 120 asbestos exposed workers, who have worked since 1985 to $2003 y$, and 121 non-exposed workers have used as a control group. A clinical (anamnesis, physical examination), radiological (chest ex-ray, accounted by ILO' 80 ) and spirometry was done of dust exposed workers and non-exposed screened individuals were performed. A non-parametric statistical analysis with significance calculation (P) by usage SPSS software was done. Additionally, the all number and the incidence of malignant mesothelioma per 100000 person's population were investigated.Results and discussion. The dust diseases in exposed workers up to 1985 y decrease. We detected new diagnosed pneumoconioses and occupational dust bronchitis in patients with 10+years exposure to quartz and asbestos, who have been worked up to $1985 \mathrm{y}$. It has been accounted an increase of the incidence of malignant mesothelioma during the period $1990-2000 \mathrm{y}$. Conclusions. We prognosticate a rise in the incidence of silicosis, asbestosis, and mesothelioma in the future 10-20 yrs due to low quality of the preventive measures in the basic dust industries in Bulgaria during the last two decades. We consider it is necessary to perform wide studies in dust exposed workers, and to create a register of the dust, as well as of the exposed workers, and of the dust diseases in Bulgaria.
\end{abstract}

Key words: pneumoconioses, occupational dust bronchitis, mesothelioma, epidemiology, trends, prognosis, prevention

\section{INTRODUCTION}

The main groups of occupational diseases (OD) included in the List on occupational diseases (LOD) in Bulgaria are: 1.OD, caused by non-organic and organic dusts, 2 . OD due to physical factors (noise, local and whole body vibrations, variable microclimate, ionizing and non-ionizing factors, electro-magnetic fields, lasers, static and dynamic physical loading, systemic micro-traumas, motive monotony in psycho-sensor tension, loading of vocal organs), 3. OD related

Address for correspondence:

E. Petrova, DSC, Centre on Occupational Diseases; University Hospital Saint Ivan Rilski; 15 Bull. Akademic Ivan Geshov 1431 Sofia

e-mail:mdepetrova@yahoo.com to biological agents: micro-organisms (bacteria, viruses, rickettsia, mycotic agents, intracellular micro-organisms), plant and animal products, 4. OD related to industrial dust прах and 5. OD related to industrial products, non-classified elsewhere.

Up to now the most diagnosed and most widespread in Bulgaria were the OD of the nervous system, as well as the OD of the muscle-skeletal system and the OD lung diseases due to industrial dust. The non-organic dusts kept their morbid effect a long period after discontinuation of the dust risk work. The most important in the practice are the specific and non-specific benign and malignant occupational dust diseases with lung and non-pulmonary localization. The basic dust lung diseases (silicosis, asbestosis, silicatoses, pneumoconioses due to metal containing dusts, chronic obstructive and non-obstructive bronchitis, asbes- 


\section{Petrova E.}

tos related malignant diseases etc) were characterized with progressive development, progressive work disability and an untimely death. The disability due to these diseases leads to serious moral, social and material damages for the patients, employers and the community. It requires to be created a realistic and a correct statistics, an effective prevention, a screening, a dynamic surveillance, a treatment and an expertise on occupational dust diseases. We present the trends of the most significant occupational dust lung diseases in Bulgaria. The problems of occupational and occupational dust diseases are discussed in a number papers of some Bulgarian authors (1-6).

The aim of the study was to present the main groups of occupational diseases In Bulgaria, as well as the epidemiological trends and the prognosis of the benign and malignant occupational dust diseases in workers exposed to non-organic dust up to 1985 y, and during 1985 - 2003 periods, as well as to propose ideas for adequate medical check up.

\section{MATERIAL AND METHODS}

The all number of patients with benign and malignant occupational dust diseases in Bulgaria during the period 1985 $-2000 y$ was investigated. The information was obtained by the last regional departments for medical service of pneumoconiosis in Bulgaria. Additionally, we investigated dust diseases in 116 miners from brown coal mining in Bobov dol mine, 113p. - from black coal mining in Balkan mine, 53p. - from anthracite coal mining in Antra, 198 - from lead-zinc ore mining in Lucky, Gorubso, and 120 asbestos exposed workers, who have worked since 1985 to 2003y, and 121 non-exposed workers have used as a control group. A clinical (anamnesis, physical examination), radiological (chest ex-ray, accounted by ILO'80) and spirometry was done of dust exposed workers and non-exposed screened individuals were performed. A non-parametric statistical analysis with significance calculation $(\mathrm{P})$ by usage SPSS software was done. Additionally, the all number and the incidence of malignant mesothelioma per 100000 person's population were investigated.

\section{RESULTS}

Trends in the absolute number of occupational dust lung diseases in workers exposed to quartz containing dust until 1985 year.

The absolute number of occupational dust lung diseases in workers exposed to quartz containing dust until 1985 year is presented. There were a least absolute number of patients with silicosis, and silicosis + silicotuberculosis in 1994y and 1997y. The absolute number of patients with silicosis and silicosis + silicotuberculosis was little higher in 1988y. The curve of the all number of patients has obtained a plateau-like form during the $1988-2000 y$ period. In 2000y the absolute number of patients with silicosis + silicotubercu- losis was about 5000, and only with silicoses - under 4000 . The curve of the silicotuberculosis showed an approximately horizontal configuration during the $1985-2000 y$ period. The most significant decrease of patients' absolute number with silicotuberculosis was in 1993 year. It has found a harsh increasing trend in absolute number of workers with borderline silicosis, really endangered of silicosis during the 1990-1995y period. The workers have been exposed to quartz containing dust until 1985y. In 1995y the absolute number of borderline silicoses in Bulgaria was 24000. The number of borderline silicoses has decreased up to 22000 in $2000 y$.

The study of the trend in the absolute number of patients with asbestosis, asbestos related pleural fibroses and plaques in Bulgaria has showed variations during 1985-2000 period. The absolute number of patients with pulmonary and pleural asbestos related benign diseases was lowest in $1985 \mathrm{y}$ (136 patients). There was a trend of increase in the absolute number of the asbestos related diseases up to 1990 year (201 patients). It has registered a slight decrease in the number of asbestos related parenchymal and pleural diseases (up to 199p.) between 1995 year and 2000 year. In study of the dynamics of the absolute number of silicatoses (talcosis + kaolinosis + mixed mineral pneumoconioses) in Bulgaria during 1985 2000 period was established a slight increase of the total number of patients with silicatoses in the country (from 79 p. - in 1985y up to 99p - in 1990y). There was a trend of harsh increasing of the silicatoses (199p. in 1995y) and following horizontal configuration of the curve during the 1995-2000 period. The established little absolute number of the silicatoses in Bulgaria was related with bad detection of the diseases related to luck of knowledge of the physicians and the other clinicians in this area. It was detected a rise in the absolute number of patients with welders' pneumoconiosis. The registered number of patients varied between 70 and 80 in 1990y. The number of the patients with welders' pneumoconiosis has increased harshly (128p. - in 1995y) during the 1990-2000y and has occurred light increase up to 145 in $2000 \mathrm{y}$.

There was detected a decrease in the absolute number of the patients with silicosis, asbestosis, asbestos related fibrosis and plaques, as well as talcosis, kaolinosis, mixed mineral pneumoconioses, and pneumoconioses due to metal containing dust during the period $1985-2000 \mathrm{y}$. These trend was related to a decrease of number of the ex-miners, who have been worked in the dry drilling or dry and wet drilling period in underground mines in Bulgaria in the last 2-4 decades to $1985 \mathrm{y}$, as well as high latent incidence of pneumoconioses in present dust exposed workers in the country due to insufficient effectiveness of the prophylaxis, bad qualification of GP and other clinicians who take part in the prophylactic screenings of dust exposed workers as well as serious problems in the organization and in financial cover for activities on occupational diseases medical field in Bulgaria. 
Occupational diseases. Epidemiological trends of the occupational dust diseases ...

\section{Epidemiological trends of pneumoconioses in coal and ore miners in Bulgaria in $2003 y$ due to quartz containing occupational dust exposure after 1985 year}

Unclear epidemiological situation in the field of occupational dust diseases in quartz and asbestos exposed workers has motivated our study, aimed to detect the dust diseases in some basic coal, ore mines and in groups of asbestos exposed individuals, who worked after 1985 year. The total number of the present coal and ore mines and ex-miner in Bulgaria was about 100000 in 2003y. Last survived and present asbestos exposed workers in Bulgaria were 27000 until 2003y. The studies on the dust levels at the work places in underground mines in Bulgaria during the 1985 2003 period accounted many time exceeding permissible levels dust concentration in anthracite coal mine "Antra", black coal mine "Balkan 2000", and in brown coal mine "Bobov dol". In 2003y we established a dominating share of initial p1/1 silicoses in miners from "Balkan 2000", followed by miners from "Bobov dol", in quartz and asbestos exposed workers, and the minimal was the share of the miners from "Antra". The borderline $\mathrm{p} 0 / 1$ and $\mathrm{p} 1 / 0$ silicoses has dominated in "Lucky" and "Balkan 2000" $(\mathrm{P}<0.0001)$ - Fig. 1 .

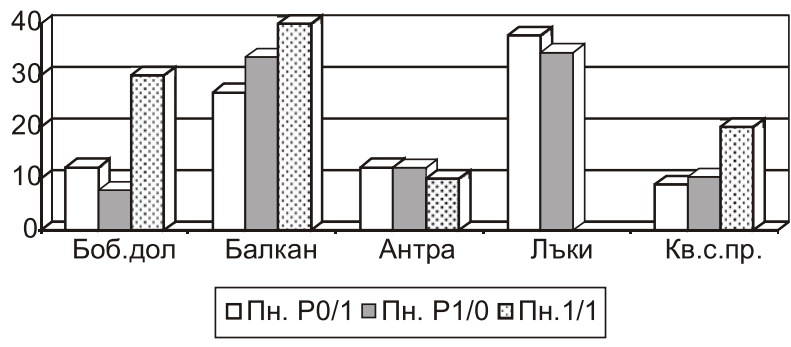

(Statistics: Pearson Chi-Square $=762.244 ; P<0.0001$ ) Figure 1. Initial and borderline silicoses in different underground mines in Bulgaria in 2003y

Chronic dust occupational; bronchitis in different groups dust exposed workers who have been worked after 1985 year

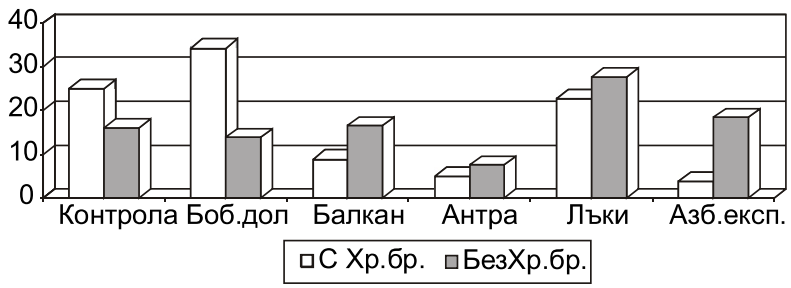

Figure 2. Occupational dust chronic bronchitis in workers' groups exposed to dust at different work places after $1985 y$

The chronic bronchitis dominated in dust exposed workers from "Bobov dol", who have been exposed at high concentrations of brown coal dust, containing middle level quartz compound. The next is the share of chronic bronchitis amongst underground ore miners in "Lucky" mine, fol- lowed by non-exposed control group, and the lower are the relative shares of the chronic bronchitis in workers from black mining in "Balkan 2000", miners from anthracite mining in "Antra" and the lowest is the share of bronchitis in asbestos exposed workers. In cases of luck of significant contra-criteria, the chronic bronchitis in miners from "Bobov dol" mine can be defined as an occupational dust chronic bronchitis (Fig. 2).

\section{Benign asbestos related diseases in Bulgaria in 2003 year in asbestos exposed workers after 1985 year}

We established a dominating share of manifest asbestosis in workers' group from thermo-electric-power-station "Bobov dol", followed by asbestos exposed workers' group in non-ferrous metals' production in Plovdiv, and the last was the share of the workers' group in production of asbestos break linings in Breznik. Similar was the distribution of the boundary forms of asbestosis. Most expressed was the share of benign asbestos related pleural diseases of the workers' group in non-ferrous metals' production in Plovdiv, followed by the workers in thermo-electric-power-station "Bobov dol". We detected asbestos related diseases from unknown risk industries until the screening in 2003 year (Fig. 3).

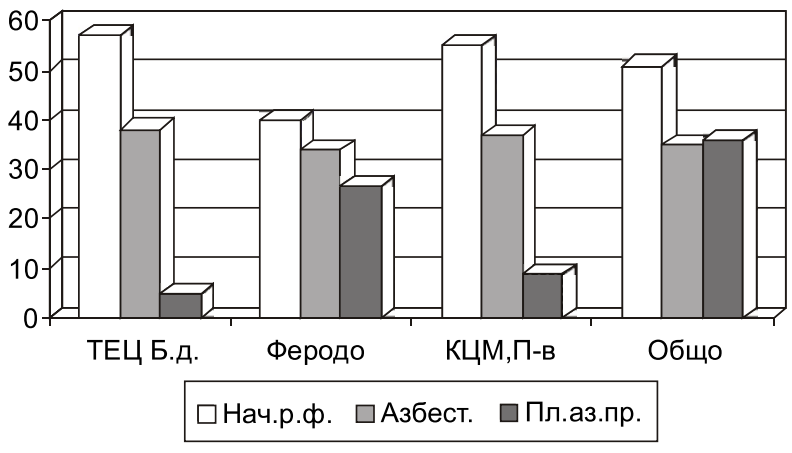

Figure 3. Asbestos related diseases in workers' groups exposed to asbestos after 1985 year

\section{Epidemiological trends in malignant mesothelioma during the 1990 - 2000y period}

We detected a trend of an increasing of pleural and peritoneal malignant mesothelioma during the eleven years period (1990 - 2000y), and non-clear tendency in the distribution of the rare and difficult diagnosed pericardial mesothelioma (Figure 4). According to Helsinki criteria, $80 \%$ of the cases of malignant mesothelioma are related to asbestos exposure, mainly connected with work places. The dominated prevalence of pleural mesothelioma in the age groups after 60ys, 50-59 and 40-49 years was related with 20 - 40 years latent period since initial asbestos exposure till appearance of the disease (Figure 5). The new diagnosed cases of mesothelioma in Bulgaria in the 1990 - 2000years period have been exposed to asbestos during the 70-80 years of the XX Century. These years were known as a 
period of most intensive usage of asbestos in Bulgarian industry.

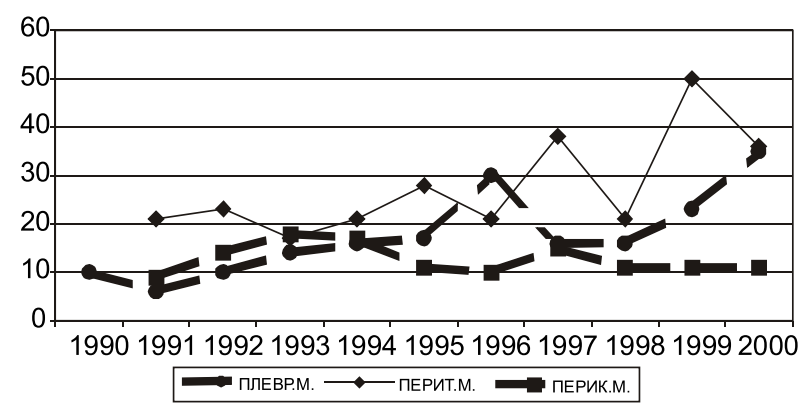

Figure 4. Epidemiological trends in malignant mesothelioma during the 1990-2000y period

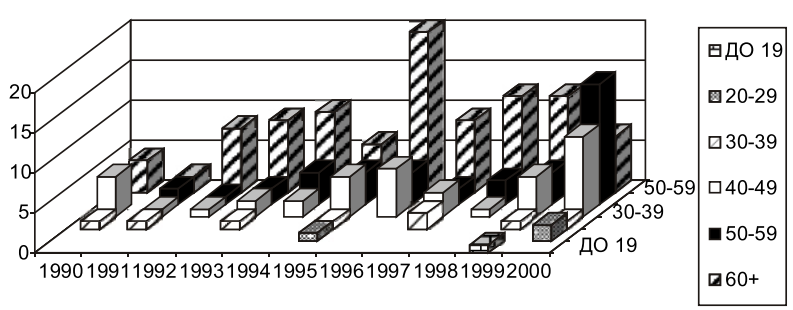

Figure 5. Age distribution of malignant mesothelioma in Bulgaria in 1990 - 2000 y period

\section{Prognosis}

Bearing in mind the contingents of dust exposed workers, the high dust levels in the basic Bulgarian mines until 1985 year, workers' asbestos exposure, dose-effect relationship studies as well as the dynamics of the basic dust diseases in Bulgaria, we prognosticate:

1. Increasing prevalence of silicosis in coal and ore mining during the future 10-20 years period

2. Increasing prevalence of asbestosis and benign asbestos related pleural diseases during the future 10-15 years

3. Increasing prevalence of malignant mesothelioma during the future 10 years

4. Continuing prevalence of mesothelioma with a gradual drop during the future 20-40 years period

5. Increasing prevalence of occupational dust chronic bronchitis from the brown coal mining in "Bobov dol"

6. Future prevalence of reticular-micronodal pneumoconioses in ex- and present miners from "Balkan 2000" and "Antra" mines

7. Taking in mind the detected initial pneumoconioses in 2003 year, as well as preliminary information for an endangering of silicosis in "Gorubso" ore mine, we propose an actual measurement and an assessment of the dust concentrations at the work places in the mine. The prophylaxis of the dust exposed workers requires: 1. improvement the working conditions including invention of dust free technologies, and adequate ventilation equipment, 2. initiation a list of the dust exposed workers in each risk industry branch in Bulgaria, 3. realization of a systemic monitoring and invention of register for the dust risk factor in each industry branch in the country, 4 . initiation regular and effective preliminary and periodical check ups for the dust exposed contingents, 5. initiation a contemporary surveillance system and health monitoring for dust exposed ex-workers, and 6. initiation a software product for registration and surveillance.

The achievement a qualitative and early diagnosis in pneumoconiosis is related with:

1. using of the ILO International Classification of Pneumoconioses, Geneva, 1980 at all levels of medical service, 2. wide using of the contemporary diagnostic image methods (chest CT, chest HRCT, etc) and invasive diagnostic methods (FBS with TBLB, TT, TS, TTANB, BALF etc) and realizing mineralogical, histological, cytological and electron microscopic investigations, 3. improvement the quality of the preliminary and periodical check-ups and reading of the lung radiographies by specialists in this field, 4. initiation an education of GPs, radiologists and other clinicians, and 5. an adequate financial cover for the diagnostics and treatment of the occupational dust diseases.

\section{REFERENCES}

1. Petrova E. The occupational dust lung diseases caused by non-organic dusts. Dissertation for DSC, Sofia, 2005 (in Bulgarian, English abstract).

2. Petrova E (2004) Handbook on occupational dust lung diseases. S., Ministry of labour and social politic "Work conditions found", Invest press AD (in Bulgarian).

3. Petrova E (2005) Occupational diseases due to non-organic dusts. Sofia, FUT, 2005 (in Bulgarian).

4. Petrova E. Picture of occupational diseases in basic industries in Bulgaria during the 1985 - 2000 period, Scripta periodica, VII, 2004, 3 (In Bulgarian, , English abstract).

5. Petrova E. Welder's pneumoconiosis. Scripta periodica, Vol.VIII, 2005, 2, 10-19 (in Bulgarian, English abstract).

6. Petrova E. Epidemiological tendencies in malignant mesotheliomas in Bulgaria during the 1990-2000 period. Acta Medica Bulgarica, XXXII, 2005, 2, 9-11 (in English). 